Research Perspective

\title{
SOCS1: phosphorylation, dimerization and tumor suppression
}

\author{
Frédéric Lessard ${ }^{1}$, Emmanuelle Saint-Germain ${ }^{1}$, Lian Mignacca $^{1}$ and Gerardo \\ Ferbeyre $^{1,2}$ \\ ${ }^{1}$ Département de Biochimie et Médecine Moléculaire, Université de Montréal, Montréal, Québec, Canada \\ ${ }^{2}$ CRCHUM, Montréal, Québec, Canada \\ Correspondence to: Gerardo Ferbeyre, email: g.ferbeyre@umontreal.ca \\ Keywords: P53, SRC kinases, cytokine singling, SH2 domains \\ Received: October 02, $2019 \quad$ Accepted: October 13,2019 Published: January 1, 2020
}

Copyright: Lessard et al. This is an open-access article distributed under the terms of the Creative Commons Attribution License 3.0 (CC BY 3.0), which permits unrestricted use, distribution, and reproduction in any medium, provided the original author and source are credited.

\section{ABSTRACT}

Suppressor of cytokine signaling (SOCS) family members are upregulated following JAK-STAT pathway activation by cytokines. SOCS proteins are recognized inhibitors of cytokine signaling playing roles in cell growth and differentiation. Moreover, SOCS1 and SOCS3 have been shown to be involved in tumor suppression through their ability to interact with p53 leading to the activation of its transcriptional program and showing the implication of SOCS family members in the regulation of apoptosis, ferroptosis and senescence. More recently, we demonstrated that the SRC family of non-receptor tyrosine kinases (SFK) can phosphorylate SOCS1 leading to its homodimerization and inhibiting its interaction with p53. Then, we reactivated the SOCS1-p53 tumor suppressor axis with the SFK inhibitor dasatinib in combination with the p53 activating compound PRIMA. This work suggests new avenues for cancer treatment and leaves open several new questions that deserve to be addressed.

\section{INTRODUCTION}

SOCS1 (Suppressor Of Cytokine Signaling-1) is a member of the SOCS family comprising 8 members (SOCS1, 2, 3, 4, 5, 6, 7, and cytokine-inducible SH2 domain-containing protein (CISH)) which all contain an SH2 (Src Homology 2) domain and a SOCS box region [1-3]. Some members of the SOCS family (CISH, SOCS1, SOCS2 and SOCS3) are induced following JAK-STAT signaling activation and are also recognized retro-inhibitors of cytokine signaling (Cartoon: \#1 and \#2) [1-3]. We recently demonstrated that SOCS1 can be phosphorylated on tyrosine $(\mathrm{Y}) 80$ in its extended $\mathrm{SH} 2$ domain by members of the SRC family of non-receptor tyrosine kinases (SFKs) including YES1, SRC, LCK, LYN and BLK (Cartoon: \#3) [4]. Tyrosine phosphorylation in the SH2 domain of SRC, LCK and LYN has been reported to decrease or impair binding to pY-peptides [5-7]. Because SH2 domains are structurally very similar, we were accordingly able to demonstrate that a phosphomimetic substitution of SOCS1 $\mathrm{Y}[80]$ in the $\mathrm{SH} 2$ domain is less effective to inhibit JAKSTAT signaling (Cartoon: \#4) [4]. In line with these results, it is tempting to speculate that other $\mathrm{SH} 2$ domain containing members of the SOCS family could be phosphorylated by members of the SRC family of non-receptor tyrosine kinases (Cartoon: \#5). If confirmed, this will expand our knowledge on SOCS-family functions following non-receptor tyrosine kinase activation.

While performing in vitro kinase assays, we found that SOCS1 can dimerize and that the dimeric form is strongly phosphorylated compared to the monomeric form (Cartoon: \#3) [4]. This is the first demonstration of a SOCS family member dimerization and we confirmed this ability in cellulo by pulling down a MYC-tagged version of SOCS1 following immunoprecipitation of a FLAG-tagged SOCS1 [4]. Of note, deletion of the SOCS box region did not abrogate the dimerization suggesting that the $\mathrm{SH} 2$ domain might be implicated in SOCS1 homodimerization [4]. Considering that all member of the SOCS family contain an $\mathrm{SH} 2$ domain and a variable $\mathrm{N}$-terminal region, which could be involved in homodimerization, it is plausible for other SOCS members to have the capacity to homodimerize (Cartoon: \#5). If this is confirmed, we will have to consider the possibility 
of heterodimerization between the different SOCS family members.

SOCS1 has been shown to be a tumor suppressor with the ability to bridge p53 and ATM at DNA damage foci leading to $\mathrm{p} 53$ phosphorylation and a subsequent increase in its transcriptional activity (Cartoon: \#6) $[8,9]$. This direct interaction involves the SH2 domain of SOCS1 and the p53 N-terminal transactivation domain 2 (TAD2) $[4,8]$. We have shown that a phosphomimetic substitution of SOCS1 $\mathrm{Y}[80]$ is less effective to interact with p53 (Cartoon: \#7) [4]. Moreover, the inhibition of SFKs with the small molecule dasatinib $[10,11]$ in combination with the compound PRIMA, which reactivates mutant p53 [12-14], leads to an increase of the endogenous p53-SOCS1 interaction in human lymphoma SU-DHL4 cells [4]. These results, combined with immunohistochemistry studies, suggested that SFK inhibitors could be an option to reactivate p53-SOCS1 tumor suppressor activity in patients with lymphomas [4]. Another interesting fact is a study conducted in many DLBCL cell lines treated with dasatinib. The results of the study showed that cells treated with dasatinib demonstrated a decreased SFK phosphorylation and decreased cellular proliferation. More interestingly, the cells did not respond to imatinib, a specific $\mathrm{ABL}$ inhibitor, suggesting that the action of dasatinib (an ABL-SFK inhibitor) was dependent on SFKs rather than ABL inhibition [15, 16]. Our results show that the p53-SOCS1 interaction and tumor suppressor activity is modulated by the SFKs. SOCS1 phosphorylation by SFKs leads to its dimerization which inhibits its anti-tumor activity by preventing its interaction with p53 [4]. It would be interesting to evaluate the ability of other pan or more specific tyrosine kinase inhibitors to activate the p53-SOCS1 tumor suppressor axis. Furthermore, our laboratory has shown that the SH2 domain of SOCS3 can interact with p53 by GST pull-down (unpublished data) and some groups have shown interaction of SOCS3 with p53 [17, 18]. It is then likely that phosphorylation of SOCS3 by the SRC family also controls its ability to regulate $\mathrm{p} 53$.

Our work sheds light on the dynamic regulation of SOCS1 by the SRC family of tyrosine kinases and provide convincing evidence for SOCS1 dimerization. These two events, phosphorylation and dimerization regulate the p53SOCS1 tumor suppressor axis [4] and open new avenues in the regulation of SOCS proteins and in cytokine signaling. Moreover, our results suggest that a subset of patients with lymphomas could benefit from treatment with inhibitors of SRC family kinases [4]. Finally, it has been shown that HER+ breast cancer cells treated with SRC inhibitors allowed tumor regression in xenografts and inhibition of proliferation [19] in a

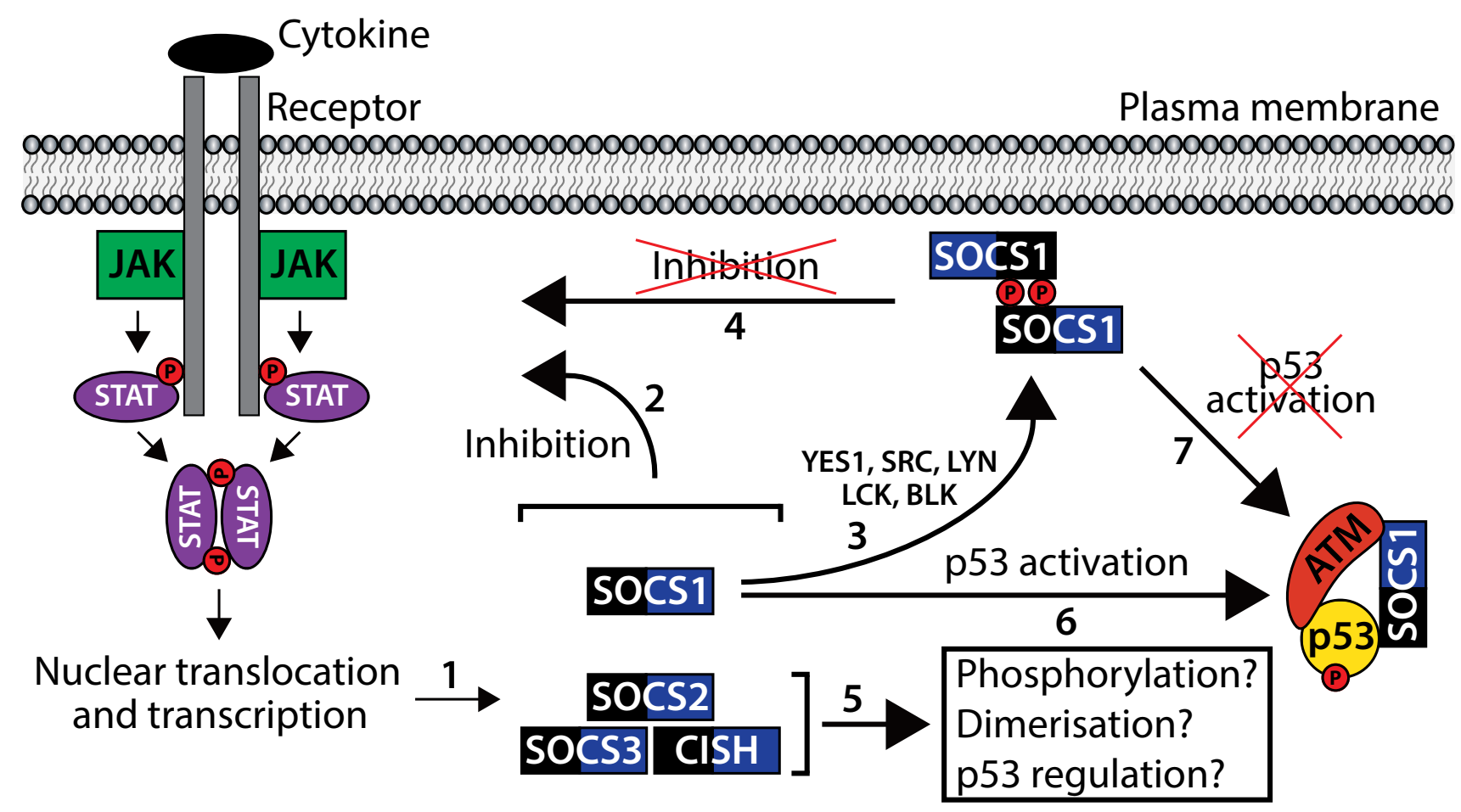

(P) = Phosphorylation

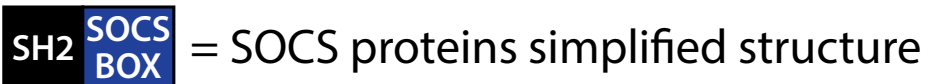

Figure 1: STAT signaling leads to SOCS1, SOCS2, SOCS3 and CISH transcription and protein accumulation. 2- SOCS implication in inhibition of JAK-STAT signaling. 3- SOCS1 phosphorylation by the SRC family of non-receptor tyrosine kinases leads to SOCS1 homodimerization. 4- Phosphorylated SOCS1 is suggested to be less effective to inhibit JAK-STAT signaling. 5- Other members of the SOCS protein-family might be phosphorylated, could dimerize and could be implicated in p53 regulation. 6- Tumor suppressor role of SOCS1. 7- Phosphorylated SOCS1 is suggested to be less effective to activate p53. 
p53 dependent manner, suggesting that our results are relevant to other cancer models.

\section{AUTHOR CONTRIBUTIONS}

E.S-G., L.M., and G.F. participated in manuscript revisions and corrections. F.L. wrote the manuscript.

\section{ACKNOWLEDGMENTS}

This work was funded by a grant from the Canadian Institute of Health and Research (CIHR-MOP229774 to G. Ferbeyre). F. Lessard is supported by FRQS (Fonds de Recherche du Québec-Santé) and CRS (Cancer Research Society). G. Ferbeyre is supported by the CIBC chair for breast cancer research at the CRCHUM.

\section{CONFLICTS OF INTEREST}

The authors declare no potential conflicts of interest.

\section{REFERENCES}

1. Krebs DL, Hilton DJ. SOCS proteins: negative regulators of cytokine signaling. Stem Cells. 2001; 19:378-87. https:// doi.org/10.1634/stemcells.19-5-378. [PMID:11553846]

2. Alexander WS, Hilton DJ. The role of suppressors of cytokine signaling (SOCS) proteins in regulation of the immune response. Annu Rev Immunol. 2004; 22:503-29. https://doi.org/10.1146/annurev. immunol.22.091003.090312. [PMID:15032587]

3. Durham GA, Williams JJ, Nasim MT, Palmer TM. Targeting SOCS Proteins to Control JAK-STAT Signalling in Disease. Trends Pharmacol Sci. 2019; 40:298-308. https://doi. org/10.1016/j.tips.2019.03.001. [PMID:30948191]

4. Saint-Germain E, Mignacca L, Huot G, Acevedo M, Moineau-Vallée K, Calabrese V, Bourdeau V, Rowell MC, Ilangumaran S, Lessard F, Ferbeyre G. Phosphorylation of SOCS1 Inhibits the SOCS1-p53 Tumor Suppressor Axis. Cancer Res. 2019; 79:3306-19. https://doi. org/10.1158/0008-5472.CAN-18-1503. [PMID:31101761]

5. Jin LL, Wybenga-Groot LE, Tong J, Taylor P, Minden MD, Trudel S, McGlade CJ, Moran MF. Tyrosine phosphorylation of the Lyn Src homology 2 (SH2) domain modulates its binding affinity and specificity. Mol Cell Proteomics. 2015; 14:695-706. https://doi.org/10.1074/ mcp.M114.044404. [PMID:25587033]

6. Stover DR, Furet P, Lydon NB. Modulation of the SH2 binding specificity and kinase activity of Src by tyrosine phosphorylation within its SH2 domain. J Biol Chem. 1996; 271:12481-87. https://doi.org/10.1074/jbc.271.21.12481. [PMID:8647855]

7. Couture C, Songyang Z, Jascur T, Williams S, Tailor
P, Cantley LC, Mustelin T. Regulation of the Lck SH2 domain by tyrosine phosphorylation. J Biol Chem. 1996; 271:24880-84. https://doi.org/10.1074/jbc.271.40.24880. [PMID:8798764]

8. Calabrese V, Mallette FA, Deschênes-Simard X, Ramanathan S, Gagnon J, Moores A, Ilangumaran S, Ferbeyre G. SOCS1 links cytokine signaling to p53 and senescence. Mol Cell. 2009; 36:754-67. https://doi. org/10.1016/j.molcel.2009.09.044. [PMID:20005840]

9. Cui X, Shan X, Qian J, Ji Q, Wang L, Wang X, Li M, Ding H, Liu Q, Chen L, Zhang D, Ni R. The suppressor of cytokine signaling SOCS1 promotes apoptosis of intestinal epithelial cells via p53 signaling in Crohn's disease. Exp Mol Pathol. 2016; 101:1-11. https://doi.org/10.1016/j. yexmp.2016.05.011. [PMID:27236107]

10. Dos Santos C, McDonald T, Ho YW, Liu H, Lin A, Forman SJ, Kuo YH, Bhatia R. The Src and c-Kit kinase inhibitor dasatinib enhances p53-mediated targeting of human acute myeloid leukemia stem cells by chemotherapeutic agents. Blood. 2013; 122:1900-13. https://doi.org/10.1182/ blood-2012-11-466425. [PMID:23896410]

11. Araujo J, Logothetis C. Dasatinib: a potent SRC inhibitor in clinical development for the treatment of solid tumors. Cancer Treat Rev. 2010; 36:492-500. https://doi. org/10.1016/j.ctrv.2010.02.015. [PMID:20226597]

12. Lambert JM, Gorzov P, Veprintsev DB, Söderqvist M, Segerbäck D, Bergman J, Fersht AR, Hainaut P, Wiman KG, Bykov VJ. PRIMA-1 reactivates mutant p53 by covalent binding to the core domain. Cancer Cell. 2009; 15:376-88. https://doi.org/10.1016/j.ccr.2009.03.003. [PMID:19411067]

13. Bykov VJ, Wiman KG. Mutant p53 reactivation by small molecules makes its way to the clinic. FEBS Lett. 2014; 588:2622-27. https://doi.org/10.1016/j.febslet.2014.04.017. [PMID:24768524]

14. Bykov VJ, Eriksson SE, Bianchi J, Wiman KG. Targeting mutant p53 for efficient cancer therapy. Nat Rev Cancer. 2018; 18:89-102. https://doi.org/10.1038/nrc.2017.109. [PMID:29242642]

15. Yang C, Lu P, Lee FY, Chadburn A, Barrientos JC, Leonard JP, Ye F, Zhang D, Knowles DM, Wang YL. Tyrosine kinase inhibition in diffuse large B-cell lymphoma: molecular basis for antitumor activity and drug resistance of dasatinib. Leukemia. 2008; 22:1755-66. https://doi.org/10.1038/ leu.2008.163. [PMID:18596745]

16. Hollmann CA, Tzankov A, Martínez-Marignac VL, Baker K, Grygorczyk C, Grygorczyk R, Foulkes W, Nadeau J, Dirnhofer S, Aloyz R. Therapeutic implications of Src independent calcium mobilization in diffuse large B-cell lymphoma. Leuk Res. 2010; 34:585-93. https://doi. org/10.1016/j.leukres.2009.08.030. [PMID:19758698]

17. Kong X, Feng D, Wang H, Hong F, Bertola A, Wang FS, Gao B. Interleukin-22 induces hepatic stellate cell 
senescence and restricts liver fibrosis in mice. Hepatology. 2012; 56:1150-59. https://doi.org/10.1002/hep.25744. [PMID:22473749]

18. Chen J, Pan J, Wang J, Song K, Zhu D, Huang C, Duan Y. Soluble egg antigens of Schistosoma japonicum induce senescence in activated hepatic stellate cells by activation of the STAT3/p53/p21 pathway. Sci Rep. 2016; 6:30957. https://doi.org/10.1038/srep30957. [PMID:27489164]

19. Abdullah C, Korkaya H, Iizuka S, Courtneidge SA. SRC Increases MYC mRNA Expression in Estrogen Receptor-Positive Breast Cancer via mRNA Stabilization and Inhibition of p53 Function. Mol Cell Biol. 2018; 38:e0463-17. https://doi.org/10.1128/MCB.00463-17. [PMID:29263157] 